\title{
Benefits of an Updated Mapping between the NIST Cybersecurity Framework and the NERC Critical Infrastructure Protection Standards
}

Jeffrey Marron

Applied Cybersecurity Division

Information Technology Laboratory

Avi Gopstein

Smart Grid and Cyber Physical Systems Office

Engineering Laboratory

Daniel Bogle

North American Electric Reliability Corporation (NERC)

Atlanta, Georgia

September 29, 2021

This publication is available free of charge from:

https://doi.org/10.6028/NIST.CSWP.09292021

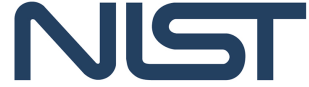

National Institute of Standards and Technology

U.S. Department of Commerce

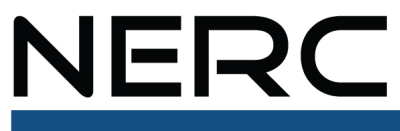

NORTH AMERICAN ELECTRIC RELIABILITY CORPORATION 


\begin{abstract}
This white paper highlights a recent mapping effort between the North American Electric Reliability Corporation (NERC) Critical Infrastructure Protection (CIP) standards and the NIST Cybersecurity Framework. Mappings of these two frameworks have been performed in the past; this effort updated the mapping to reflect the currently enforceable NERC CIP Standards and the NIST Cybersecurity Framework v1.1. This white paper helps organizations understand how they can use the mapping to achieve a more mature CIP requirement compliance program while improving their security posture and potentially reducing the organization's security and business risk.
\end{abstract}

\title{
Keywords
}

Bulk Electric System (BES); Critical Infrastructure Protection (CIP); Cybersecurity Capability Maturity Model (C2M2); North American Electric Reliability Corporation (NERC); National Institute of Standards and Technology (NIST); Online Informative References (OLIR); Reliability and Security Technical Committee; Security Working Group (SWG).

\section{Disclaimer}

Any mention of commercial products or reference to commercial organizations is for information only; it does not imply recommendation or endorsement by NIST, nor does it imply that the products mentioned are necessarily the best available for the purpose.

\section{Additional Information}

For additional information on NIST's Cybersecurity programs, projects, and publications, visit the Computer Security Resource Center. Information on other efforts at NIST, in the Information Technology Laboratory (ITL), and on the NIST Smart Grid Program is also available. Visit NERC for information about NERC programs, projects, and initiatives.

\section{Comments on this publication may be submitted to:}

National Institute of Standards and Technology

Attn: Applied Cybersecurity Division, Information Technology Laboratory

100 Bureau Drive (Mail Stop 2000) Gaithersburg, MD 20899-2000

Email: NISTCSF-NERCCIP-Mapping@nist.gov

All comments are subject to release under the Freedom of Information Act (FOIA). 


\section{Supplemental Content}

The final mapping between the NERC CIP standards and the NIST Cybersecurity Framework (CSF) v1.1 referenced in this white paper can be found at https://doi.org/10.18434/mds2-2348. The file named "NIST CSF v1.1 to NERC CIP FINAL.XLSX" is the complete mapping. There is also a README file explaining the mapping data set and its background and uses. 


\section{NERC CIP and the Cybersecurity Framework}

Every organization in the electricity sector knows that cybersecurity is already a major challenge. There are a variety of standards and resources that organizations are either required or encouraged to use in managing their unique cybersecurity-related risks. A recent mapping initiative between two major cybersecurity guidance documents can help organizations mature and align their compliance and security programs and better manage risks.

The North American Electric Reliability Corporation (NERC) Critical Infrastructure Protection (CIP) Reliability Standards [NERC CIP] are a set of requirements designed to mitigate the risk of a compromise that could lead to misoperation or instability in the Bulk Electric System (BES). The scope of the CIP Cyber Security Standards is restricted to BES Cyber Systems that would impact the reliable operation of the BES. The Reliability Standards cover topics like the identification and protection of BES Cyber Assets, defining logical isolation perimeters, personnel and training, BES Cyber System security management, disaster recovery planning, physical security, and supply chain risk management.

The Framework for Improving Critical Infrastructure Cybersecurity - commonly referred to as the Cybersecurity Framework [NIST CSF] - is a risk-based approach to help owners and operators of critical infrastructure manage cybersecurity-related risk in a manner complementary to an organization's existing cybersecurity and risk management processes. The CSF was developed by the National Institute of Standards and Technology (NIST) in close collaboration with the private sector. It is used by organizations of all sizes, in a variety of sectors, and globally. The Framework Core (Core) uses common language to provide a catalog of desired cybersecurity activities and outcomes. Using five concurrent and continuous Functions as an organizing structure - Identify, Protect, Detect, Respond, and Recover - the Core provides a high-level, strategic view of an organization's management lifecycle for cybersecurity risk. Underlying the five concurrent Functions, the Core identifies 23 Categories (as shown in Table 1) and 108 Subcategories that describe discrete cybersecurity outcomes. The Core also presents informative references for each of the Subcategories that include industry standards, guidelines, and practices. 
Table 1 - CSF Functions and Categories

\begin{tabular}{|c|c|c|}
\hline Function & $\begin{array}{l}\text { Category Unique } \\
\text { Identifier }\end{array}$ & Category \\
\hline \multirow{6}{*}{ Identify } & ID. AM & Asset Management \\
\hline & ID. BE & Business Environment \\
\hline & ID. GV & Governance \\
\hline & ID.RA & Risk Assessment \\
\hline & ID.RM & Risk Management Strategy \\
\hline & ID.SC & Supply Chain Risk Management \\
\hline \multirow{6}{*}{ Protect } & PR.AC & Identity Management and Access Control \\
\hline & PR.AT & Awareness and Training \\
\hline & PR.DS & Data Security \\
\hline & PR.IP & Information Protection and Procedures \\
\hline & PR.MA & Maintenance \\
\hline & PR.PT & Protective Technology \\
\hline \multirow{3}{*}{ Detect } & DE.AE & Anomalies and Events \\
\hline & DE.CM & Security Continuous Monitoring \\
\hline & DE.DP & Detection Processes \\
\hline \multirow{5}{*}{ Respond } & RS.RP & Response Planning \\
\hline & RS.CO & Communications \\
\hline & RS.AN & Analysis \\
\hline & RS.MI & Mitigation \\
\hline & RS.IM & Improvements \\
\hline \multirow{3}{*}{ Recover } & RC.RP & Recovery Planning \\
\hline & RC.IM & Improvements \\
\hline & RC.CO & Communications \\
\hline
\end{tabular}

These informative references provide practical suggestions for how organizations can achieve the desired outcome of each Subcategory. An example of two Subcategories within the Supply Chain Risk Management Category is shown in Table 2. A dynamic set of informative references is available through the NIST Online Informative References (OLIR) Program [OLIR]. 
Table 2 - Two Subcategories and Relevant Informative References

\begin{tabular}{|c|c|c|c|}
\hline Function & Category & Subcategory & Informative References \\
\hline \multirow{2}{*}{$\begin{array}{l}\text { IDENTIFY } \\
\text { (ID) }\end{array}$} & \multirow{2}{*}{$\begin{array}{l}\text { Supply Chain Risk } \\
\text { Management (ID.SC): } \\
\text { The organization's } \\
\text { priorities, constraints, } \\
\text { risk tolerances, and } \\
\text { assumptions are } \\
\text { established and used } \\
\text { to support risk } \\
\text { decisions associated } \\
\text { with managing supply } \\
\text { chain risk. The } \\
\text { organization has } \\
\text { established and } \\
\text { implemented the } \\
\text { processes to identify, } \\
\text { assess, and manage } \\
\text { supply chain risks. }\end{array}$} & $\begin{array}{l}\text { ID.SC-1: Cyber supply } \\
\text { chain risk management } \\
\text { processes are identified, } \\
\text { established, assessed, } \\
\text { managed, and agreed to } \\
\text { by organizational } \\
\text { stakeholders }\end{array}$ & $\begin{array}{l}\text { - CIS CSC } 4 \\
\text { - COBIT 5 APO10.01, APO10.04, APO12.04, } \\
\text { APO12.05, APO13.02, BAI01.03, BAI02.03, } \\
\text { BAI04.02 } \\
\text { - ISA 62443-2-1:2009 4.3.4.2 } \\
\text { - ISO/IEC 27001:2013 A.15.1.1, A.15.1.2, } \\
\text { A.15.1.3, A.15.2.1, A.15.2.2 } \\
\text { - NIST SP 800-53 Rev. } 4 \text { SA-9, SA-12, PM-9 }\end{array}$ \\
\hline & & $\begin{array}{l}\text { ID.SC-2: Suppliers and } \\
\text { third-party partners of } \\
\text { information systems, } \\
\text { components, and } \\
\text { services are identified, } \\
\text { prioritized, and assessed } \\
\text { using a cyber supply } \\
\text { chain risk assessment } \\
\text { process }\end{array}$ & $\begin{array}{l}\text { - COBIT 5 APO10.01, APO10.02, APO10.04, } \\
\text { APO10.05, APO12.01, APO12.02, } \\
\text { APO12.03, APO12.04, APO12.05, } \\
\text { APO12.06, APO13.02, BAI02.03 } \\
\text { - ISA 62443-2-1:2009 4.2.3.1, 4.2.3.2, } \\
\text { 4.2.3.3, 4.2.3.4, 4.2.3.6, 4.2.3.8, 4.2.3.9, } \\
\text { 4.2.3.10, 4.2.3.12, 4.2.3.13, 4.2.3.14 } \\
\text { - ISO/IEC 27001:2013 A.15.2.1, A.15.2.2 } \\
\text { - NIST SP 800-53 Rev. } 4 \text { RA-2, RA-3, SA-12, } \\
\text { SA-14, SA-15, PM-9 }\end{array}$ \\
\hline
\end{tabular}

These two approaches to cybersecurity -NERC's Standards-driven cybersecurity requirements and NIST's framework for assessing and mitigating cybersecurity risk-are complementary. A recent International Energy Agency report [IEA] on cyber resilience in electricity systems emphasizes the need to combine requirements-driven regulatory approaches with frameworkbased management strategies to ensure power grid cybersecurity. NERC and NIST personnel have partnered to update the mapping between NERC CIP and the CSF to provide confidence to organizations seeking to secure their electric system infrastructure and operations.

\section{The Mapping}

An initial mapping between the CSF v1.0 and NERC CIP Standards (both Versions 3 and 5) was completed in late 2014 by the NERC Control Systems Security Working Group, which was part of the former NERC Critical Infrastructure Protection Committee. Since that time, both the NERC CIP Standards and the CSF have been updated, and a new mapping was needed. Building on the 2014 effort, NERC and NIST updated the mapping to reflect the CSF v1.1 and latest NERC CIP Reliability Standards. In the spring of 2020, the NERC Compliance Input Working Group - now known as the Security Working Group (SWG) that is a part of the Reliability and Security Technical Committee — reviewed the mapping and provided recommendations for improving the resource.

The final mapping [Mapping] includes three distinctive spreadsheet tabs, described as follows:

- NIST CSF 1.1 to CIP v5 is oriented toward the CSF Subcategories. This tab shows the NERC CIP Standards that map to each Subcategory of the CSF Core. A row is included 
for each unique mapping between a NERC CIP Standard and a CSF Subcategory. For that reason, a Subcategory may appear in consecutive rows. For example, the Subcategory ID.AM-1 has two rows because two NERC CIP Standards map to that Subcategory. Each row also includes a justification for the mapping, provides mappings to relevant Cybersecurity Capability Maturity Model (C2M2) practices [C2M2], and lists industry recommended implementation guidance.

- CIPv5 to CSF 1.1 XREF reverses the mapping (i.e., focusing on NERC CIP Standards) and lists the CSF Subcategories that align with each NERC CIP Standard requirement. A NERC CIP Standard (e.g., CIP-002-5.1a-R1) may span multiple rows if it contains multiple requirements (e.g., CIP-002-5.1a-R1-1.1).

- Pivot shows the same information as the "CIPv5 to CSF 1.1 XREF" tab but is configurable. Users can expand or minimize each NERC CIP Standard. They can also choose additional information to view, including Function, Category, and Subcategory information from the Cybersecurity Framework; C2M2 maturity indicator levels for each Subcategory; or guidance from the first tab.

\section{Compliance and Security}

The mapping spreadsheets show which Subcategories - and the informative references by extension-can help organizations achieve a more mature CIP requirement compliance program. Along with the compliance maturity, the user gains additional resources on how to improve their security posture and potentially reduce their organization's security and business risks. The OLIR program can help users find additional informative references for each CIP Requirement, making the compliance programs more efficient and effective.

To gain a quick understanding of a Subcategory and how it could apply to the CIP program, a user can look at the Guidance column in the "NIST CSF 1.1 to CIP v5" tab. Industry subject matter experts developed this guidance; however, this guidance is limited to a generic, low level of detail.

In contrast to the high-level guidance, an organization can utilize the mapping, along with the informative references, to develop an in-depth program to reduce risks across the board. The wealth of information in the Core's informative references is immense; this mapping offers a good first step for users unsure of where to start. For example, if the goal is to implement a more mature baseline program, the pivot table can be used to look for CIP-010-2 Requirement R1; eight Subcategories that map to that CIP Requirement are shown. Consider two of these Subcategories: Protect (PR) Data Security (DS) Subcategories 6 and 7. PR.DS-6 states, "Integrity checking mechanisms are used to verify software, firmware, and information integrity," and PR.DS-7 states, "the development and testing environment(s) are separate from the production environment." These outcomes sound desirable, but it is not immediately clear from this description how an organization could achieve that goal. The Core's list of informative references can help users understand the steps their organization can take to realize the outcomes. For PR.DS-6, the Core lists these informative references: 
- Center for Internet Security (CIS) Controls [CIS]

○ 2 and 3

- Control Objectives for Information and Related Technologies (COBIT) 5 [COBIT]

- API01.06, BAI06-01, and DSS06-02

- International Society of Automation (ISA) 62443-3-3:2013 [ISA]

○ $\quad$ SR 3.1, SR 3.3, SR 3.4, and SR 3.8

- International Organization for Standardization (ISO)/International Electrotechnical Commission (IEC) 27001:2013 [ISO]

○ A.12.2.1, A.12.5.1, A.14.1.2, A.14.1.3, and A.14.2.4

- NIST Special Publication (SP) 800-53 Rev 4 [SP800-53]

- SC-16 and SI-17

With these informative references, an organization will be able to develop an action plan. An organization could add even more depth by looking at NIST's OLIR program for additional informative references. The mapping is intended to help an organization mature its compliance and security programs, as they should be aligned. Subject matter experts are developing a companion tool to facilitate industry use of the NERC CIP-to-CSF mapping. The tool uses the mapping to help organizations self-assess their current security and compliance posture and develop an improvement plan for addressing identified gaps. The tool is the result of a collaborative effort by industry volunteers from NERC's Reliability and Security Technical Committee Security Working Group and representatives from NERC and NIST. 


\section{References}

[C2M2] Department of Energy (2021) Cybersecurity Capability Maturity Model. Available at https://www.energy.gov/ceser/cybersecurity-capability-maturitymodel-c2m2

[CIS] Center for Internet Security (2021) CIS Controls V8. Available at https://www.cisecurity.org/controls/

[COBIT] Information Systems Audit and Control Association (ISACA) (2021) Control Objectives for Information and Related Technologies. Available at https://www.isaca.org/resources/cobit

[IEA] International Energy Agency (2021) Enhancing Cyber Resilience in Electricity Systems. Available at https://webstore.iea.org/download/direct/4359

[ISA] International Society of Automation (2013) ISA 62443-3-3:2013 - Security for industrial automation and control systems Part 3-3: System security requirements and security levels (ISA, North Carolina, USA). Available at https://www.isa.org/products/ansi-isa-62443-3-3-99-03-03-2013-security-for-indu

[ISO] International Organization for Standardization/International Electrotechnical Commission (2013) ISO/IEC 27001:2013 - Information technology - Security techniques - Information security management systems - Requirements (ISO, Geneva, Switzerland). Available at https://www.iso.org/standard/54534.html

[Mapping] National Institute of Standards and Technology and North American Electric Reliability Corporation (2020) Mapping of NIST Cybersecurity Framework v1.1 to NERC CIP Reliability Standards. https://doi.org/10.18434/mds2-2348

[NERC CIP] North American Electric Reliability Corporation (2021) NERC CIP Enforceable Standards. Available at https://www.nerc.com/pa/Stand/Pages/CIPStandards.aspx

[NIST CSF] National Institute of Standards and Technology (2018) Framework for Improving Critical Infrastructure Cybersecurity, Version 1.1. (National Institute of Standards and Technology, Gaithersburg, MD). https://doi.org/10.6028/NIST.CSWP.04162018

[OLIR] National Institute of Standards and Technology (2021) National Online Informative References Program. Available at https://csrc.nist.gov/projects/olir

[SP800-53] Joint Task Force Transformation Initiative (2013) Security and Privacy Controls for Federal Information Systems and Organizations. (National Institute of Standards and Technology, Gaithersburg, MD), NIST Special Publication (SP) 800-53, Rev. 4, Includes updates as of January 22, 2015. https://doi.org/10.6028/NIST.SP.800-53r4 